Seeking Asylum-Holding Patterns:

The 2020 Ballina Region for Refugees Poetry Prize

\author{
Bill Boyd (ed.) \\ Southern Cross University \\ Ballina Region for Refugees \\ hendboyd2477@gmail.com \\ Emma Doolan (ed.) \\ Southern Cross University \\ Emma.Doolan@scu.edu.au \\ Ruth Henderson (ed.) \\ Ballina Region for Refugees \\ hendboyd2477@gmail.com
}

\begin{abstract}
Copyright@ 2021 Bill Boyd, Emma Doolan, and Ruth Henderson. This text may be archived and redistributed both in electronic form and in hard copy, provided that the author and journal are properly cited and no fee is charged, in accordance with our Creative Commons Licence.
\end{abstract}

\begin{abstract}
Poetry provides valuable and insightful ways to explore and record social and political experiences and engagements. The plight of refugees and people seeking asylum in Australia is well known. Community groups such as the Ballina Region for Refugees provide support to refugees and asylum seekers both in Australia and offshore. To help raise awareness and validate the experience of refugees and asylum seekers, the Ballina Region for Refugees runs an annual Poetry Prize. The 2020 Ballina Region for Refugees Poetry Prize theme was Seeking Asylum-Holding Patterns. This article presents the winning and highly commended poems, along with poems by refugee and asylum seeker poets. Poems from both insider witnesses - refugees and asylum seekers - and outsider witnesses - poets who seek to express an empathy with the plight of refugees and asylum seekers - have contributed to this collection. From haunting statements of human dissolution that should strike fear into anyone's heart, through glimpses of hope, the poems explore the trails of asylum seeking and the dysfunctionality of the aftermath.
\end{abstract}

Keywords: refugee; asylum seeker; poetry; social advocacy; writing for social justice; poetry as social activism; insider witness 


\title{
The 2020 Ballina Region for Refugees Poetry Prize
}

\author{
Poetry is nearer to vital truth than history. Plato
}

\author{
A poet's work is to name the unnameable, to point at frauds, to take sides, start \\ arguments, shape the world and stop it from going to sleep. Salman Rushdie
}

In early 2020, the Australian refugee support group Ballina Region for Refugees (BR4R) invited submissions to its 2020 Seeking Asylum - Holding Patterns Poetry Prize. The Poetry Prize is a collaboration between the Ballina Region for Refugees group and Southern Cross University. The prize celebrates the positive contributions refugees make to our communities, and it acknowledges the circumstances that forced them flee their homelands and request refuge in Australia. The prize was open to writers around Australia, including refugees and asylum seekers detained in Australian detention centres and hotel 'prisons'.

This year's competition theme was Seeking Asylum-Holding Patterns. Poets were invited to submit poems of up to fifty lines that considered the variety of roles holding patterns occupy in refugee and asylum seeker experiences. The invitation provided the following provocation:

\begin{abstract}
Planes circle, unable to land. Queues stretch past the horizon. Waiting periods extend beyond memory. Names slide from one form to the next. A backlog of unanswered questions, a hallway that never ends, a compound that never closes. The holding pattern can be approached from a broad variety of perspectives, and contributors may consider the ways in which holding patterns signify delay, disruption and discouragement, bureaucratic complexity, the stasis of legal and financial processes, systematic and institutional structures that obstruct or delay action-but also holding onto, being folded into, patterns of family, friendship, community, and culture.
\end{abstract}

In inviting Australians of all backgrounds to engage creatively with the concept of seeking asylum, the prize encourages the community to connect empathetically and imaginatively with the realities inhabited by refugees and asylum seekers. This is not to say the prize gives licence for writers to appropriate the lived experience of refugees and asylum seekers. Rather, it seeks to draw on poetry's ability to connect us to one another, to foster empathy and understanding, and to inspire change ${ }^{i}$. Creative expression, including poetry, provides a means to critiqueAustralia's current inhumane policies and stance with regard to asylum seekers ${ }^{\text {ii }}$ to a global audience and citizenry. In this sense, the publication of these poems may be seen as an enabling act in a very positive and powerful sense. Furthermore, the collection of poems presented here also continues an emerging tradition in which borders between the notion of a professional poet and a poet who writes out of the pressure of an historical moment are being questioned and broken down ${ }^{\text {iii. }}$. Unsettling the dominant paradigm of authority and authorship in an important process in re-setting social understandings of refugees and asylum seekers. Behrouz Boochani's recent book, No friend but the mountains, highlights the power of such re-author(is)ing of writing ${ }^{\mathrm{iv}}$. 
Some of the poems presented in this collection draw, in part, on the tradition of the poetry of witness" . This is poetry of poets whose lives were shaped "by unsurmountable forces, thrown off course, even - at worst - destroyed ... [who composed poems] at an extreme of human endurance, on the brink of breakdown or death"vi. They bear witness to historical events and the impacts of these events. Importantly, they bear witness to events for which ordinary language is inadequate in articulating a full reaction, a task to which some would argue poetry is particularly suited, in "its ability to accommodate the sublime, the ineffable, that of which we cannot speak"vii.

Other poems in this collection also, however, draw on outsider perspectives, those of poets who have not necessarily or directly experienced asylum seeking or being a refugee, yet who seek ways to empathise with refugees and asylum seekers. Likewise, poetry offers a suitable language. While the concept of empathy is problematic in contemporary poetry ${ }^{\text {viii }}$, it appears to provide a powerful medium for building social connections in times of stress ${ }^{\mathrm{ix}}$. As one study of post-9/11 outsider witness poetry suggests, "third-party witnesses, like poets, [have the potential to] provide new understandings of historical responsibility and national identity in the [national] imagination" " They seek, as do others, possibilities to create space to listen to the stories being told and, in doing so, assist in exploring social identity, and through coconstructing new realities and promote healing ${ }^{\mathrm{xi}}$.

And yet, despite the personal perspective of the witness, is there more to the poetry? Does it have an ability to mould the course of events? The Palestinian poet Mahmoud Darwish noted, "I thought poetry could change everything, could change history and could humanize ... but now I think that poetry changes only the poet." ${ }^{\text {xii }}$ His comments, must be taken in context; he is described as having written under a state of siege. As Almog Behar ${ }^{\text {xiii notes, }}$ "perhaps Mahmoud Darwish sought to break the siege with his poetry and believed in poetry's power to stand up to armies and to reality. Yet he admitted, more than once, that poetry was defeated by reality." Nevertheless, we can take Darwish's potent comments as a challenge for poets and poetry readers alike, a challenge to persist on a journey of change. While it may, therefore, be argued that the poetry in this collection may not change the past of suppression and dehumanisation of refugees and asylum seekers in Australia, the fact of this very publication articulates a belief that such a collection of poems can change something. The highly personal and experiential nature of the poems, whether by refugees and asylum seekers or by others, supports Darwish's presumption that poetry can change the writers of these poems. However, in a nation that persists in a draconian approach to refugee and asylum seeker policies and treatment ${ }^{\mathrm{xiv}}$, there is an urgent need to effect change beyond the poet - at least, amongst ourselves as readers and amongst our communities. There is a need to, for example, lend our voices to welcoming and supporting refugees and asylum seekers in the hopes that, eventually, we can change the course of events, and that Australia can become a more humane nation. We can gain strength from other fields of social justice action. If such an aspiration had little validity, the growth of poetry in, for example, the school education of social justice would be viewed as futile; there are many examples where this is not considered to be $\mathrm{so}^{\mathrm{xv}}$. This collection supports such optimism.

Turning to the poetry presented in this collection, it is satisfying to note the extent to which the Seeking Asylum poetry prize's aims were achieved. Encouraging and supporting refugee 
and asylum seeker voices resulted in strong submissions from both writers identifying as refugees or asylum seekers, and from others.

Our third-place winner, Yasaman Bagheri, oscillates between painful hope and excoriating anger in her poem Empty Envelope, as she reflects on the experience of children born under the shadow of Australia's border policies, policies that declare that "We will make sure / You will never have a home".

Jalal Mahamede's haunting Dear Gardener, in looking into the depths of his being, laments his loss of being and connection, concluding with an indictment of the condition we allow our refugees and asylum seekers to reach: "Now I stayed with the dark forest, where are you? I call you from the depths of my being, Oh Lord, I am losing my mind". "Nothing is in place anymore", he continues in his second poem, "You try to talk to me, my ears do not hear ...". His accompanying art speaks to the dissolution of being expressed so eloquently in his poems.

Kazem Kazemi's The Monday So Gloomy Without You reiterates the loneliness and the loss: "In your absence, I leave the world". What a state to find one's self in! And yet Kazemi seems to find a glimmer of hope, closing on, "I wish you'd been here to close my eyes / They'll be opened, because of my waiting for you". He continues in his second poem, Freedom, to place his lack of freedom up front, in terms all readers must surely be able to understand, and all readers must surely fear. Our fear should be amplified by Kazemi's simple question: "Will I see freedom again?". Kazemi, however, still hangs onto the possibility of release, of sorts: "It is too hard with my heart / full of emotions and love / I must go somewhere else / where I can be a stranger again".

Farhad Bandesh's poem, also titled Freedom, likewise takes us to dark places, the corners of our dark shadows where the refugee is thrown, dark places where" my body is in tatters ... the delicacy of my soul and body is no more ...". The real fear - a fear we should all acknowledge - is the fear of never seeing light again, and of our souls being forever black.

From the outside, Victoria King wonders, "Is this me?", in her first-place winning poem Can I Hold a Village?. "What's it like?", muses second-place winner Genevieve Barr in Disappeared. Both poems enter imaginatively into the experience of the asylum seeker, the repeated questions in each marking the poets 'progress towards an understanding that is ultimately partial and elusive. The questions remain unanswered, but an avenue has been opened, a hand extended. In her second poem, Holding pattern: a sestina, Victoria King continues her imagining by seeking to imagine the journey of promises, given and broken, faced by refugees. These are broken promises that result in incarceration "-But I am here. Still. And time / Is marked each day by the strike and whisper / Of a rock against a whitewashed wall that never / Ceases to be temporary. ..." The fundamental insult to any person: "For never shall this place be home".

The dispossession continues: Kate Cantrell's Map-Scrapping reminds us of other holding patterns, of how events create forgetting. "A Dutch man went continent hunting," Kate tells us, "and they still left us off the map in 1982 ... It's a national embarrassment we said when Baz forgot Tasmania." How easy is it to forget? Kim Lateef provides something of an answer 
in her poem Loose Thread: "my mother pulls at a loose silver thread / and i want to scream / at how quickly / thread / unravels". A timely reminder, indeed.

Ion Corcos, in his poem Handkerchief, draws on Abdurrahim Buza's The Refugees (1957) to paint a deceptively simple picture of the refugee. Drawing images upon image, perhaps metaphor upon metaphor, Ion reminds us of the humanity of each and every individual refugee. He reminds us, however, of the incremental tearing away of that humanity during the flight: "... He wears no shoes, limps, / his pants torn at the knees. ... No lentil soup, no potatoes tonight. ... The road is long; they will not sleep." Are the wolves who, in the final line, howl on the mountain slopes mere wild animals ...?

Otto De Pele's poem Azadî - Kurdish for freedom - reflects on a refugee artist's success, "His art hung in local galleries as an expression of ambition for freedom", tempered by the years and cycles of detention. "There are other worlds we may wish for our very own self" the poet states, closing on the words of a refugee who has given the poet permission to name him, Harhad: "Stolen from me, years of life, how easily we break each other". There is a lesson for us all: no matter what freedom we eventually obtain, the past of pain, the pain of the past, remains. Helen Gearing breathes life into the almost comical dysfunctionality of displaced lives in her poem, Gentle dystopia. The details and coping are important: "Widowed, we share a house riddled with unlabeled teas, pickled limes / and a friendship that reads like a marriage palimpsest ... we are hungry / and ridiculous side by side / in white-pimpled pyjamas". The past will never be silent.

Fadi Jan's three bird poems, Finch, Dove, and Sparrow, draw on the fragility of life. Life, we are reminded, is so easily dismantled and disrupted. Seduced into the gentle world of small birds - are we not all just small birds? - readily and instantly destroyed, we are gently shocked into the realization that nothing will ever be the same again. Rebecca Sargeant's Sovereign Borderlands, the final poem in this collection, brings us back to the human reality of power and sovereignty, of dispossession and detention. This is what Fadi Jan's birds experience, had they been people such as you and me, but "hands tied", ready to run, until, in closing, "from the terror of having to look / into light-coloured eyes / and see all the ayes in favour / and all the I's left to drown / in the bottom of the deep blue sea sea sea".

Below are presented the three winning entries in the 2020 Seeking Asylum-Holding Patterns poetry prize, followed by a shortlist of entries by poets from refugee and asylum seeker backgrounds, and finally a selection of highly commended entries.

\section{The 2020 Ballina Region for Refugees Poetry Prize winning entries}

\section{"Can I hold a village?" Victoria King \\ First Place}

Can one person hold a village? Bear the message of lineage?

Can one person hold a people, a country, a faith, a race, 
A way of seeing, of being?

A legacy?

Is this me?

Could I be that container, floating on waters

Captured and caught and still holding that message,

As a mother to my daughter?

That message whose nuance is so rich and so deep, so pungently technicoloursweet

And then agonisingly elusive and fleet

But there, like a handprint

Indescribably perfect.

For yes, that message lies in me, swells through me

In the deep, blood-heavy thud in me,

Swelling and abating, flood-like

Washing, enveloping, leaving me wanting

Gasping, for I am unable not to hold this message

And tend it, and send it

In the milk of my breast

With the heft of my chest

Along the glide of my breath

Through the slick of my sweat

Imbued in my smiles, my tears, my cries, denials

My lullabies to my child.

Can one person whisper the wilds

Of the shushing trees that push and ease

The bulge of their girth through rock-layered earth?

Can they breathe the plumes of blue sky crags and silver streams

Of smoke curls leaving evening fires?

Can one person perspire

The honey-rich sweetness of dates hanging uneaten?

Or hum the buzzing burr of flies

Snatching at dust-filled eyes

That are deep and brimming with love.

Am I enough?

My mother held all this in me

For me

As did her mother, and her mother, and her mother

.... And so on forever.

Our heredity, our legacy.

But now, how can I find a way?

A castaway, no longer there 
Encumbered, deracinated, gasping for air

Grasping

For the clutch of home, for the certainty of knowing.

I am suffocating, alienated, carved in two by the currents that rage in me,

Claw at me.

And yet their power enables me.

And so determinedly, I make my plea:

My child, let me try.

\section{"Disappeared" \\ Genevieve Ross Barr \\ Second Place}

Day breaks, out of tune,

and morning finds its way, half-heartedly

to its well-worn pedestal.

Stale air, and the sheets are stained again

with the boredom of insistence of existence.

A howling routine.

A calendar is checked,

(always full of hope that it will tell me something more).

Is it yesterday? Tomorrow? Or today?

I position myself, straight-backed upon the waiting room chair

and waste away the beginning of another, other day.

There's a lethargy in here.

Harsh words scrape at the door.

An afternoon hides behind household chores.

I have seen the undead blinking,

as I sit giggling at the in-joke

written long ago today.

What's it like to have never been?

To turn a corner, never seen. To turn another ...

Where was I? And now I'm not.

What's it like to be in between?

A time ... a place ... My defining moment.

What's it like to have disappeared?

Or worse; thrown out with the trash

and pissed on by the cat.

What's it like to have disappeared? 
An empty space.

A weeping sore.

A crashing bore.

A deaf ear turned.

A history burned.

A future scorned.

A lethargy born.

What's it like to be in between?

Is it like a tiresome day? Is it like a routine way?

And not soon enough, evening arrives

and extinguishes any hope of an unexpected tomorrow.

\section{"Empty Envelope" \\ Yasaman Bagheri}

Third Place

Falling off the sinking boat

With our hands held against the waves,

We kept the pattern to rescue

Every second's worth and stretched to a lifetime.

Inside the cloud of spilled gasoline and blood

When hope was sinking down

Hands reached to rescue.

Our disappeared boat was given a name,

(U)niform (L)ima (A)lpha.

As if water had washed our names away;

Instead, numbers had appeared

From one to a hundred and two.

We were (re)named and handed an envelope -

A message of hope.

Time worked differently in there:

We watched it, counted it;

They got paid for it;

We suffered it, lost it;

Inside the reports never read.

We were kids born between policies.

The Border Force man spoke to us of laws.

Laws denied us, detained us. 
Laws always designed against us.

When he sent out his men and

they had our throats in their hands,

I thought about how

"Boat" came before "People"

And "Border" before "Force".

This was the message of hope:

We opened it, an empty envelope,

Full of unwritten words:

"We will make sure

you will never have a home."

Every year we are less human

More popular election-winning lies.

You can rise from the ocean

With blood-coloured wings

Sharks will let you pass - unharmed.

But you will drown in prison camps.

Close your eyes this time,

Let me build you a boat

From my two hands,

A boat that will set you free

From these prison camps.

You will sail to no "Shore" "Off" of our hearts;

The road you'll travel from seeking refuge to finding home,

Will not end behind a maximum-security fence;

Home will not be a place in the palm of your hands

Where you hold the tally mark of years -

(Un)lived in prison camps.

The 2020 Ballina Region for Refugees Poetry Prize poems by refugee or asylum seeker writers

\section{"Dear Gardener" \\ Jalal Mahamede}

Dear Gardener

I look into the depths of my being 
Coolabah, Nr 29, 2021, ISSN 1988-5946, Observatori: Centre d'Estudis Australians $i$ Transnacionals / Observatory: Australian and Transnational Studies Centre, Universitat de Barcelona

My whole body is shaking. The roots have turned into trees, and the trees have blossomed

But why do flowers turn black?

The branches whisper the song of sorrow in my brain

And they show me their hatred like this

It's as if their place is narrow ...

My body no longer has place for these roots and foliage

I remember one day there was a gardener pruning these leaves

The gardener also migrates

Of course he was right

Now I stayed with the dark forest, where are you? I call you from the depths of my being,

Oh Lord, I am losing my mind,

I know you won't come again ...

I fell

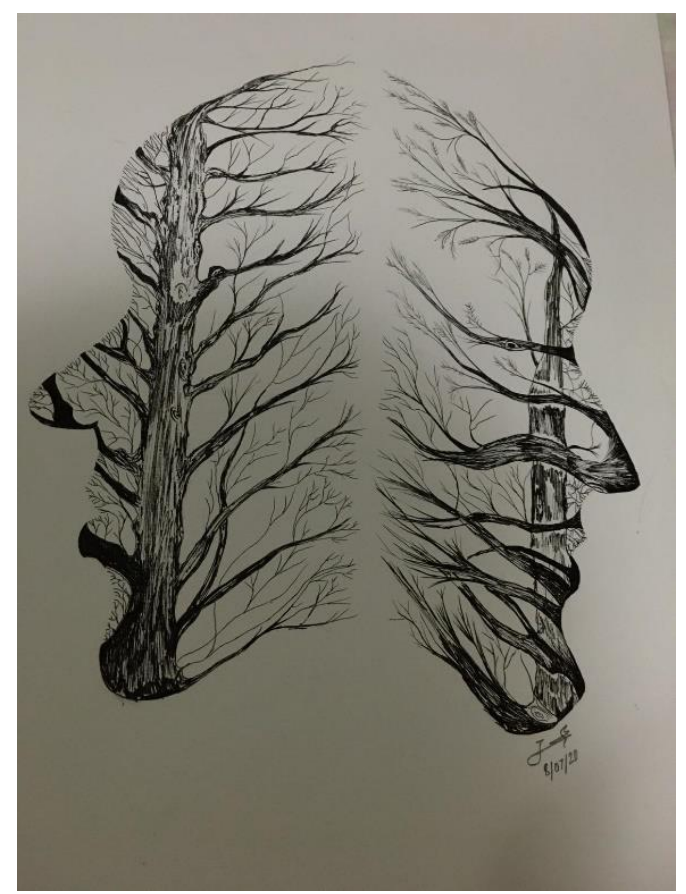




\section{"Nothing is in place anymore " Jalal Mahamede}

Nothing is in place anymore;

No more eyes or mouth can be washed

The brain it sits in the side pocket, the hands spray poison into the brain

Waiting and tiredness are long-standing habits

The mouth has nothing to say

The looks have no meaning anymore ...

Do you think like that???

Eating the blood of liver has been our daily business for a long time

the tearful eye hid in the mouth

But ...

The day will come, when you come to me, complain about the pain in your eyes

That day is too late, I know and you do not know

I spent my life in vain and it was wrong

But look in the old box, the writing is left in there for you,

Enjoy the taste and the feel of those words.

You try to talk to me, my ears do not hear,

nothing is in place...

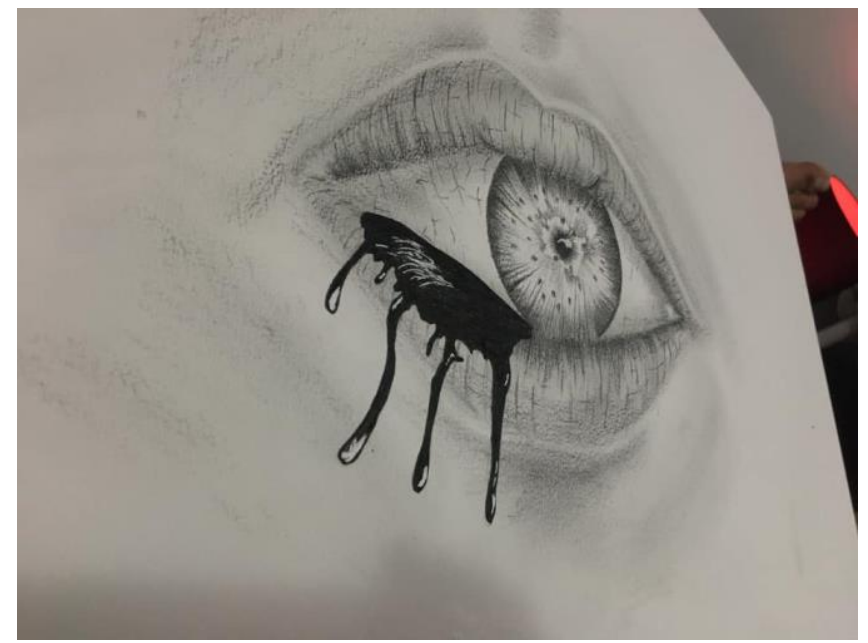

\section{"The Monday So Gloomy Without You" Kazem Kazemi}

In your absence

I leave the world

My hands want to convey

Customs of lovers and beloved

Poured water from behind me 
My tears weeping

In the absence of you

I wish you'd been here to clear the tears

And given me the power

The ease with which to go

The trees take me ahead

To the door with the frame of black

And waiting till I go

Without you

In your absence

I can't be touched by the elegance of rain

It slaps me brutally

It has my sentence in its hands

I am condemned to not see you again

My darling, the pink flowers are here

within the colour I visualize your lips

They are crying for me

In your absence

Ah what's a gloomy Monday

Far from you

In your absence

To leave the world without closed eyes

To tell the truth to you

My darling I always wanted you

I wish you'd been here to close my eyes

They'll be opened, because of my waiting for you

\section{"Freedom" \\ Kazem Kazemi}

Will I see freedom again?

My wings have become disabled

in the cage of waiting.

The vision of my eyes can't see

from behind the grid fences anymore.

Hope and love are dying in my body

I have become a stranger to myself.

Yes, it is me. I was condemned 
to say hello to people

who were born without our heart.

It is too hard with my heart

full of emotions and love

I must go somewhere else

where I can be a stranger again.

Will I see freedom again?

\section{"Freedom" \\ Farhad Bandesh}

My soul once provided

Only tranquillity

And it would not make my body impatient.

Now my soul's tenderness for my body

Has been forgotten.

My body is in tatters.

My soul follows

To notify you:

"I am talking about Freedom!

You throw me into the corners of your dark shadows.

You put me into the very depths of exile.

The delicacy of my soul and body is no more

In this endless shadow.

If this continues any longer

I will not see any more light

And my soul will be forever

Black."

The 2020 Ballina Region for Refugees Poetry Prize highly commended poems

\section{"Holding pattern: a sestina" \\ Victoria King}

He promised me the shelter of long, golden

Sunsets dripping with the mellifluence of time

And the comfort and warmth of blood.

My eyes flickered, ignoring the whisper, 
The embrace and insistence of home

That churned within as I nodded assent, never

Thinking how wrong he might be, never

Daring to believe how his treacle-golden

Tones, flowing through my home

Might seep through the cracks of time

Leaving me with just that crashing whisper

Of doubt. And so it was, with blood

Rising in my cheeks, that my blood

Money was negotiated. Never

Once did I falter as the paper whisper

Of notes of effort, the golden

Legacy of my parents 'lifetime

Folded in his palms and sauntered from my home.

It's taken me a long way from home

That money, a tectonic shift in my blood

A fissure in my existence, in distance and time

Here, in this centre in the centre of a red earth never-never

This land of blue faultless sky casts its searing golden

Eye over me and its wind carries a whisper

Of gritty resentment, to which I respond in a whisper

That I am crushed now with longing for home

For the cries of the village, the golden

Dust motes in the still air, the blood

Of goats, the curds, the flies, the familiar never-

Ending solidity of easy time.

But I am here. Still. And time

Is marked each day by the strike and whisper

Of a rock against a whitewashed wall that never

Ceases to be temporary. Where is home?

So far now, surging momentarily like blood

In shuttered memories, ghastly and golden.

This place, this time may hold me in its golden

Shadow, but the whisper of my blood

Screams defiance. For never shall this place be home. 


\section{"Map-Scrapping" \\ Kate Cantrell}

Behold the island!

Once the beating heart

of history, now clotted

and compressed

by the Roaring Forties.

I'm talking about Eddy's lighthouse

where ghost ships sail recklessly.

A Dutch man went continent hunting

and they still left us off the map in 1982.

Across the Bass, imperial wounds

bestowed in the playground

that dangerous and sub-divided land

where a boy moored himself to me

and tugging hard broke my arm

in two places. The funny bone is a joke

I don't understand.

Sant wrote close to the continent who wouldn't

make a fuss? There have been wars for less.

In the nineties the Queen had a mastectomy

the stitches would not go quietly

and had to be extracted with a plier

eight weeks later.

The Queen was unimpressed.

You see it was the nineties,

the worst decade by far.

Later Arnott's produced a biscuit

that paid homage to Ponting.

At Christmas we read a book on Kindle

How to be Invisible by J.J. Luna.

We fought about moving south

to Brisbane. This was before

Nam Le wrote The Boat

and Hanson said without irony

we're in danger of being swamped.

It's a national embarrassment we said

when Bazforgot Tasmania. 
On Friday at $5 \mathrm{pm}$

our three-year-old had a fit

in the line at Centrelink.

With a fat lip, she asked the doctor glumly

where's my lollypop?

He laughed and tickled her ribs

while she looked for something to do to him.

\section{"Loose Thread" \\ Kim Lateef}

brown-wrinkled hands against bright blue taffeta

silver-threaded patterns glint and the magpie watches us

my engagement dress before The War

... before you became a Refugee?

my mother winces as if still in disbelief

yet $i$ am a child of Refugees and i cannot wince

even if,

my only inheritance are fragments, ghosts and a silver-threaded blue dress

my only regret is drinking amniotic fluid and swallowing my mother's nightmare

of loose threads unravelling from ancestral carpets.

my mother pulls at a loose silver thread

and $\mathrm{i}$ want to scream

at how quickly

thread

unravels.

the magpie swoops

and $\mathrm{i}$ whisper into my mother's ear:

refugee is the most beautiful word in the English language.

\section{"Handkerchief" \\ Ion Corcos}

After Abdurrahim Buza's The Refugees

He carries a red bag with all their belongings, holds his wife's hand tight; 
she walks with a stick, her grey hair hard

like the barren land she has left.

He wears no shoes, limps,

his pants torn at the knees.

They press against the wind,

her white handkerchief flapping;

their grandson looks behind.

No lentil soup, no potatoes tonight.

The gallery chose a gilded frame, but their night to Greece is dark.

The boy is too young to know where they are going, why they left their home, why

his parents have been missing for three days

after men came to their door.

The road is long; they will not sleep.

Wolves howl on the mountain slopes.

\section{"Azadî" \\ Otto De Pele}

I know a man who painted

wrote songs and poetry behind bars of hope

it's been nearly seven years (or more)

of brush strokes and removed strings

that time haunts most

although I wouldn't really know such things

I've lived for 26 years in a foreign land

ancestors in wedlock from bread and wine

on a ship of crime to a massacred milestone of a society.

His art hung in local galleries as an expression of ambition for freedom

that some here could not even fathom to inhabit in patterns

misused and confused in brief fragments

of comfortable complacency. 
A cycle can last so long that its own reprieve attempts to belong although time is a story it doesn't mean justice isn't unnecessarily handled

differently.

There are other worlds we may wish for our very own self

or words to describe -

standing next to invisible chains.

The pain of being moved to a new waiting room blue lights and black crows out hotel windows detention centres attention not mentioned couldn't tell you anything politician.

Farhad sang: "Stolen from me, years of life, how easily we break each other."

Glossary: Azadî means freedom in Kurdish. Farhad is the first name of an asylum seeker who has given me permission to mention him.

\section{"Gentle dystopia" \\ Helen Gearing}

Widowed, we share a house riddled with unlabeled teas, pickled limes

and a friendship that reads like a marriage palimpsest.

Over time our outlines seep,

unheimlich heffalump our shared self-portrait.

Milne, you remind me, arrived late while you

sampled English and offshore hospitality. Now, you pretend

your English is deteriorating and foist errands you don't care for onto me.

My Farsi, meanwhile, has outgrown

its sapling aspirations. When I dream, aspirated

Zhs and $H z s$ form a staccato kaleidoscope

of orange groves, fuchsia and a family garden pregnant

with fruit ordained for export. I turn the dial, passing you

cabbage leaves and lanolin. You laugh as I nurse

your newborn - his surprise at my areola,

pale and strange as fish lips. Our voices

pulp a score of prayers, filtered from the detritus of priestly egos. Spiritual sisters, our tomes unfurl

in cascading canons while we agree the 
god of individuality is a fraud. At other times

I bad-burn the tahdig, you neglect a tissue

and we are hungry

and ridiculous side by side

in white-pimpled pyjamas.

\section{"Finch" \\ Fadi Jan}

I gather twigs and leaves and build over a street pole egress from the east side.

Now the sun burns off the crop-seeds sunflower and safflower are neglected from the country insects are no longer optional.

I lay three pale eggs one spins off and sizzles against the asphalt street-path a black bird swings down and steals the eggshells

grief runs like ash over a puddle of membrane.

Two blue eggs sit under a green-fade plumage and a crimson wrench-beak In the past plains, we cheep playfully his brown Crown grey nape my lively tail.

Shells crack at sun-down two heads pop out bare, with little grey hairs on their bodies a fresh rosy wingspan bills wide open they cry (in gesture alone).

Hung up the street pole, nestlings rest between hay, grass and cotton scruff

laughter stalks us from a distance an off-white blur glides over a kookaburra eye-striped,

we are pushed out we take our pullus and drift back to the past plains repose in a rock patch between debris and dry grass.

Two finches learn to fly 
dust storms coil over and through

another white blur seeps through the flurry

its shadow breaks evenly

something falls from its tail

grazes through a lone cloud

a whistle trails its terrene draw

amid the tender silence that ran

before.

\section{"Dove" \\ Fadi Jan}

Soft coos

a formation of doves pierces the atmosphere

wings cut through thick fog

the sun braces behind them

envelops the earth in a shadow

chatter

or turbulence or flutter

the trailblazer flatters herself mid-way

spreads her wings two-fold

layers of feathers flap in the

rage of wind

a white dove bleeds through the masking-clouds

exposed now, she is small and slender and delicate

looking closer, her wings are lined

white-lined wings on a grey-white dove

suddenly

the white clouds stain grey

shadows multiply

she is a mourning bird

she is cooing the melody of a siren call

her delicate wings are metal plates

white lines are cannon drives

she is the permanent silhouette in the grey-blue

our people are the filtrate

the masses that didn't swallow in the dust storm 
she swoops down for bone fragments and snail shells drinks from our water wells and lifts up again

\section{"Sparrow" \\ Fadi Jan}

It's the middle of the night and my tree glows aflame,

my nest blazes: dancing flames

father has too little a reaction time

I leap with wings

I don't know how to fly.

my voice box became the

black box of a plane that broke down in the middle of the ocean.

Chirrs turn-leaves and float away

I leap and land onto another bird's nest - sounds are familiar.

I sit quietly, watching the inferno and my parents 'bodies - masticate and desecrate.

Silence is the sound of cries in our inside voices.

Now, waiting and wailing, black birds surrounding,

squawking and yakking.

They investigate. Crank open my beak

digging deeper;

they search for the black box of a bird that fell from the atmosphere.

I, am a broken plane

my black box sank into the ocean;

broke against a patch of rocks; turned into a gust-storm -

ravens circle over the nest-trees;

crows rip at me.

I wake up in a cage of passerines

and mute songbirds 


\section{"Sovereign Borderlands" \\ Rebecca Sargeant}

hands tied

recedes into

recidivism of

pounding waves

fare-thee

deep in an empty

wishing-well

being demands clean hands

a sentence constructed

in local lore language

of love thy neighbour

hoodwinked by repetition

of the problem

with the pounding press

on pavement poured

on massacre site unseen

in the eye of the beholder

of the legislative body

bag of ill-fitting clothes

numbered with a price to pay

for running a way

to protect our children

from the terror of having to look

into light-coloured eyes

and see all the ayes in favour

and all the I's left to drown

in the bottom of the deep blue sea sea sea

\section{Background and context}

Ballina Region for Refugees 'vision is to welcome, respect, and support refugees and people seeking asylum. The group's goal is to promote the acceptance and integration of refugees and people seeking asylum in Australia by thinking globally and acting locally.

Ballina Region for Refugees is a community-based and volunteer-managed organisation in regional New South Wales. It is dedicated to supporting and advocating for refugees and asylum seekers, and especially supporting settlement in the rural shire of Ballina in northeastern New South Wales. Ballina Region for Refugees volunteers organise rallies, vigils, and talks to raise awareness. The group also fundraises to provide financial and 
material assistance for refugees and asylum seekers in on-shore and off-shore detention and in the community. Ballina Region for Refugees has recently joined the nationwide Community Refugee Sponsorship Initiative. As one of over twenty regional refugee support groups nationwide, the group will support refugees to settle in regional Australia. This support will include assisting with housing, employment, education, access to social services, and social integration.

The Ballina Region for Refugees poetry competition commenced in 2018, when BR4R supporter Christine Ahern offered $\$ 1,000$ for a poetry competition to broaden awareness about refugee issues. The first competition was launched during Refugee Week in 2019, with the broad theme of Seeking Asylum. BR4R received tremendous support from Dr Emma Doolan of Southern Cross University's School of Arts and Social Sciences. Emma located judges for the competition (Saba Vasefi, Manal Younus, and Ella Jeffery), created the terms and conditions, and negotiated for the winning and shortlisted poems to be published in the academic journal Social Alternatives and the creative arts journal Verity La.

Late in 2019, a long-time supporter of Ballina Region for Refugees, Louise Griffith, passed away. Her family and friends donated to BR4R in lieu of flowers. This legacy has meant that the competition can continue for a number of years. The competition is run in memory of Louise.

For this year's competition, prizes were awarded to first, second, and third place winners, and the judges were also asked to provide a shortlist as well as a list of highly commended poems from poets who identified as being from refugee or asylum seeker backgrounds. It is important that poets be allowed to self-identify as being from refugee or asylum-seeking backgrounds or to abstain from doing so; some may object to the labelling as part of the dehumanizing processes they have endured, and indeed some entrants refused or took a creative approach to answering this portion of the entry form.

The three winning entrants shared in a prize pool worth AUD \$600, with the first prize winner also receiving a one-year subscription to The Saturday Paper, and their poems are published in this issue of Coolabah, along with a number of highly commended entries from writers who self-identified as having refugee or asylum seeker backgrounds: Jalal Mahamede's Dear Gardener and Nothing is in Place Anymore (accompanied by original artworks by the author), Kazem Kazemi's The Monday So Gloomy Without You and Freedom, and Farhad Bandesh's work, also entitled Freedom. Also published here are highly commended poems by Victoria King, Kate Cantrell, Kim Lateef, Ion Corcos, Otto De Pele, Helen Gearing, Fadi Jan, and Rebecca Sargeant. In addition to this publication in Coolabah, the poems appear on the Ballina Region for Refugee website and newsletter. It is highly appropriate that this work is published by Coolabah. As the official journal of the Australian and Transnational Studies Centre at Barcelona University, Coolabah publishes original material about Australia and its place in the world, with a focus on critical engagement with contemporary issues. There can be no more critical contemporary issue than the plight and fate of refugees and migrants globally. 


\section{Acknowledgements}

For the 2020 competition, Ballina Region for Refugees has again been supported by Dr Doolan and Southern Cross University, and two of the previous years' judges - Saba Vasefi and Ella Jeffery - have returned, along with Samah Sabawi. The authors also acknowledge two anonymous reviewers of an early version of this article, and thank them for their valuable comments and suggestions.

Saba Vasefi is multi-award-winning writer, journalist, academic, poet and documentary filmmaker. She researches her Doctor of Philosophy on exilic feminist cinema studies and teaches at Macquarie University. She writes for The Guardian on the rhetoric of displacement and reports on the narratives of refugees incarcerated in Australia's detention regime. Her journalistic works have appeared on the BBC, SBS, BuzzFeed, The Age and Sydney Morning Herald. Saba was twice a judge for the prestigious Sedigheh Dolatabadi Book Prize for the Best Book on Women's Literature and Issues, as well as for the Ballina Region for Refugees (BR4R) Seeking Asylum Poetry Prize. The New South Wales Parliament House recognised Saba's success in directing the Diaspora Symposium-Social Justice Award, and commended her ongoing contribution to women's rights and social justice. Saba's poems have appeared in a variety of journals including Wasafiri Magazine of International Contemporary Writing in the UK, Australian Poetry Journal, Transnational Literature, and Anthology Solid Air: Australian \& New Zealand Spoken Word. She has been awarded the NSW Premier's Multicultural Medal in Art and Culture; an Honorary Brave Rising Star Award for her courageous writing on the gendered impacts of seeking asylum; the Commonwealth Scholarship, and The National Council of Women Award for her academic research.

Ella Jeffery is an award-winning poet. She is a recipient of the 2019 Queensland Premier's Young Publishers and Writers Award and her poetry has appeared in many journals and anthologies including Best Australian Poems, Meanjin and Griffith Review. She co-edits Stilts, a digital poetry journal, and holds a $\mathrm{PhD}$ from Queensland University of Technology, where she currently teaches creative writing. Dead Bolt is her first book, and won the Puncher \& Wattmann Prize for a First Book of Poems in 2019. She lives in Brisbane.

Samah Sabawi is a Palestinian multi-award-winning playwright, author and poet, who believes art can be a 'beautiful resistance 'against injustice, racism and oppression. Her plays include Cries from the Land (2003), Three Wishes (2008), Tales of a City by the Sea (2014) and Them (2019). Sabawi's essays and op-eds have appeared in many international newspapers. She is a frequent guest and co-presenter on 774 ABC Melbourne's Jon Faine's Conversation Hour, where she has appeared alongside Israeli writer Ari Shavit, BBC News New York and UN Correspondent Nick Bryant, actress Miriam Margolyes and others. Sabawi is a policy advisor to the Palestinian policy network Al Shabaka, and a member of the board of directors of the National Council on Canada-Arab Relations. She participated in various public forums on peace building, women in conflict areas, the Palestinian right of return, as well as various presentations for interfaith groups. In 2016, Novum Publishing released I Remember My Name: Poetry by Samah Sabawi, Ramzy Baroud and Jehan Bseiso. The anthology featured "deeply personal and deeply political expressions of three gifted Palestinian poets in exile". The book received the Middle East Monitor's 2016 Palestine Book Award. 
Prof. Bill Boyd is a Member of the Emeritus Faculty at Southern Cross University. His scholarly interests range widely across the geographical, social, cultural and education disciplines. He is a Visiting Professor of the Australian and Transnational Studies Centre at Barcelona University.

Dr Emma Doolan lectures in the School of Arts \& Social Sciences at Southern Cross University. Her research explores Gothic representations of place, particularly in writing about Australia's hinterland regions. Her practice-led doctoral thesis was completed at Queensland University of Technology in 2017.

Ruth Henderson is the current President of Ballina Region for Refugees. Ruth has been a Social Worker for over forty years.

\section{Endnotes}

' Earley, S.M., \& DeJoy, N. (2020). Image-ning the emotive power of the poetic word: Multi-layered, multi-faceted images as pathways for understanding our singular and collective lives. International Journal of the Image, 11(3), 77-93.

ii Zarzosa, H.L. (2020). Immigration detention through time. Initiatives, 25 February 2020. Rego, N., \& Gottardo, C. (2020). Australia: Australia's border and its discontents.pp. 299338 in Alberto Ares Mateos, S. J., Mauricio García, Durán, S. J., Cecilia Estrada Villaseñor, \& Juan Iglesias Martínez (Eds) (2020). Migratory Flows at the Borders of Our World, 299. Editorial Pontificia Universidad Javeriana: Bogota.

${ }^{\text {iii }}$ See for example, Rivera, T. (2013). You Have to Be What You're Talking About: Youth poets, amateur counter-conduct, and parrhesiastic value in the amateur youth poetry slam. Performance Research, 18(2), 114-123, DOI: 10.1080/13528165.2013.807175; this is an excellent account of the role of urban youth poetry and its emergence as a vibrant account of the potential of the amateur poet capture the essence of connection and feeling in contemporary social landscapes in ways that a professional poet may find irrelevant and inexpressible.

${ }^{\text {iv }}$ Boochani, B. (2018). No friend but the mountains: Writing from Manus prison. Picador Australia.

${ }^{v}$ Forché, C., \& Wu, D. (Eds.). (2014). Poetry of witness: The tradition in English, 15002001. WW Norton \& Company.

vi Forché \& Wu, op cit., p.1.

vii Forché \& Wu, op cit., p.3.

viii Veprinska, A. (2020). Empathy in Contemporary Poetry After Crisis. Springer International Publishing.

${ }^{\text {ix }}$ See, for example, the role of poetry in narrative therapy: Freedman, J., \& Combs, G. (2020). Narrative therapy, poetics and poetry: Revisiting a workshop. International Journal of Narrative Therapy \& Community Work, 2020(2), 54-57.

${ }^{x}$ Moran, M. (2020). Rummaging through the ashes: 9/11 American poetry and the transcultural counterwitness. European journal of American studies, 15(2), 18pp. DOI: 10.4000/ejas. 16018 
Coolabah, Nr 29, 2021, ISSN 1988-5946, Observatori: Centre d'Estudis Australians $i$ Transnacionals / Observatory: Australian and Transnational Studies Centre, Universitat de Barcelona

${ }^{x i}$ e.g Kreller, C. (2020). Bridging cultural divides with the power of poetry: an educator's reflection. British Journal of Guidance \& Counselling, 48(1), 78-88.

${ }^{x i i}$ Mahmoud Darwish interview with Nathalie Handal, October $21^{\text {st }} 2006$, Tribes, https://www.tribes.org/web/2006/10/22/mahmoud-darwish-palestines-poet-of-exile xiii Behar, A. (2011). Mahmoud Darwish: Poetry's state of siege. Journal of Levantine Studies, 1(1), 189-199. The quote is from page 189.

xiv Zarzosa (2020) and Rego \& Gottardo (2020), op cit.

${ }^{x v}$ e.g. Camangian, P. (2008). Untempered Tongues: Teaching performance poetry for social justice. English Teaching: Practice and Critique, 7(2), 35-55. Stovall, D. (2006). Urban poetics: Poetry, social justice and critical pedagogy in education. The Urban Review, 38(1), 63-80. Sánchez, R.M. (2007). Music and poetry as social justice texts in the secondary classroom. Theory \& Research in Social Education, 35(4), 646-666, DOI: 10.1080/00933104.2007.10473354 